\title{
Influence of polymorphism and the new trigonal modification on the mechanical response of isotactic poly(propylene-co-1-pentene- co-1-hexene) terpolymers
}

\author{
Alberto García-Peñas ${ }^{1,2,3}$, José M. Gómez-Elvira ${ }^{1}$, Vicente Lorenzo ${ }^{4}$, Ernesto Pérez ${ }^{1}$, \\ María L. Cerrada ${ }^{1}$ \\ ${ }^{1}$ Instituto de Ciencia y Tecnología de Polímeros (ICTP-CSIC), Juan de la Cierva 3, 28006 \\ Madrid, Spain \\ ${ }^{2}$ College of Materials Science and Engineering, Shenzhen Key Laboratory of Polymer Science \\ and Technology, Guangdong Research Center for Interfacial Engineering of Functional \\ Materials, Nanshan District Key Laboratory for Biopolymers and Safety Evaluation, Shenzhen \\ University, Shenzhen 518060, P.R. China
}

${ }^{3}$ Key Laboratory of Optoelectronic Devices and Systems of Ministry of Education and Guangdong Province, College of Optoelectronic Engineering, Shenzhen University, Shenzhen 518060, P. R. China

${ }^{4}$ Grupo de Investigación "POLímeros: Caracterización y Aplicaciones" (U. A. del ICTP-CSIC), E.T.S.I. Industriales, Universidad Politécnica de Madrid, José Gutiérrez Abascal 2, 28006 Madrid, Spain

Correspondence to: María L. Cerrada (mlcerrada@ictp.csic.es) 


\begin{abstract}
The mechanical response and crystalline structure have been analyzed in several propylene-co-1-pentene-co-1-hexene terpolymers. Different polymorphs are developed in these terpolymers depending on global comonomer content, 1-pentene:1-hexene ratio and thermal history. The trigonal $\delta$ crystal modification is observed in addition to monoclinic and orthorhombic crystallites and mesomorphic entities. For the terpolymers with higher comonomers contents, the mesophase and even the totally amorphous samples can be readily obtained at easily accessible cooling rates. Intensity and location of relaxation processes, values for storage and indentation modulus and hardness as well are found to be related to the type of crystallites and to the crystallinity. The variation of crystallinity upon the comonomer content is rather unusual when trigonal lattice is able to be developed if compared with that exhibited by other copolymers/terpolymers based on propylene. Because of the important effect of this variable on mechanical response and mobility within amorphous regions, relationships found in other mechanical parameters and in the relaxation associated with glass transition (location and intensity) are also uncommon. The presence of trigonal polymorph exerts a key role in those atypical dependences.
\end{abstract}

Keywords: Terpolymers; 1-pentene and 1-hexene counits; crystallinity; indentation parameters; monoclinic, orthorhombic and trigonal crystallites; mesomorphic entities. 


\section{INTRODUCTION}

Polyolefins are nowadays the most important "commodity" plastics at industrial level. Main members of this family [1] are different types of polyethylene and the isotactic polypropylene (iPP). The uses of iPP are justified due to its versatility, so that it is present in all industrial areas, like packaging, films, textiles, automotive, technical parts and consumer products. This is directly related to its very interesting polymorphic behavior and its broad spectrum of properties. Different crystal lattices can be tuned through the temperature/pressure/cooling rate imposed along processing together with the incorporation of specific nucleating additives [2-7]. Variation of microstructural features is, however, the approach that can affect more deeply the polymorphs to be developed [8-17]: $\alpha, \beta, \gamma$, and a mesomorphic form. Competition between different lattices [5] is a common fact that can be observed due to thermodynamic and kinetic considerations.

A new crystalline form was further described [18] in 2005 for propylene-hexene (iPHe) copolymers at contents higher than $10 \mathrm{~mol} \%$. The inclusion of comonomer in these crystallites triggered the obtainment of the $\delta$ polymorph [19-24] in those high compositions. This trigonal lattice was also found in the propylene-pentene (iPPe) copolymers [25-28]. The $\delta$ modification was the only one developed at contents above about $14 \mathrm{~mol} \%$, while variable proportions of trigonal and monoclinic crystals $[20,21,23,25,26,27]$ or trigonal and mesomorphic entities [28,29] were found, depending on the crystallization rate, at the compositions ranging from 8 to $13 \mathrm{~mol} \%$. Subsequently, this $\delta$ polymorph was also described for propylene-co-1-pentene-co-1hexene terpolymers [30,31] and it has been recently established in propylene-co-1pentene-co-1-heptene terpolymers [32] in spite of that the trigonal lattice was not observed in propylene-co-1-heptene copolymers [33,34] crystallized under different conditions.

Three major differences related to this trigonal lattice have been reported $[18,20,24,26,30]$ for propylene-hexene copolymers compared to those with 1-pentene at a similar comonomer composition: lower degree of crystallinity, lower melting temperature and slower crystallization rate. A progressive decrease in melting temperature and crystallinity has been found [20,24,26,27] with increasing the comonomer (hexene or pentene) content in slowly cooled specimens, as represented in Figure S1 of Supporting Information. Two distinct trends were observed: a fast 
variation up to almost $10 \mathrm{~mol} \%$ of comonomer for copolymers crystallizing in the $\alpha$ form; and a second one, with a much smaller influence, in the copolymers with higher concentration of comonomer, i.e., those crystallizing in the trigonal form. Dependence of crystallinity on composition was somewhat different in other slowly cooled copolymers of propylene-1-pentene [35] (data also depicted in Figure S1) where the presence of a minimum value is observed at contents around 8-10 mol \%, i.e., between the two aforementioned regimes. The existence of a minimum was also described for fast crystallized propylene-1-pentene-1-heptene terpolymers [32].

Few studies have been, however, devoted to evaluate the mechanical properties in these propylene based copolymers and/or terpolymers with capability of developing the trigonal form. Concerning iPHe copolymers, Poon et al. [18] observed, at hexene contents superior to $10 \mathrm{~mol} \%$, yield stress values higher than those exhibited by propylene-1-octene copolymers at similar composition, fact ascribed to the new crystalline form. De Rosa et al. [22,24] described a decrease of modulus with increasing hexene content according to the reduction of the degree of crystallinity. Values of the stress at yielding were also strongly reduced with increasing hexene concentration. Regarding iPPe copolymers, there are not mechanical parameters reported in literature at those compositions where the trigonal phase can be developed. In relation to propylene-1-pentene-1-hexene terpolymers, Boragno et al. [30] analyzed the stressstrain behavior but only for a single global composition in comonomers, around 25 mol\%, and three different pentene/hexene ratios. They found very low strengths due to the low crystallinity although mechanical parameters, like Young's modulus or yield stress, were not determined. In propylene-1-pentene-1-heptene terpolymers, GarcíaPeñas et al. [32] showed that modulus and yield stress exhibited two different trends, depending on the global composition. At low contents, values were decreasing with increasing composition independently of comonomer ratio. At composition of $10 \mathrm{~mol} \%$ or above, those mechanical parameters were strongly dependent on 1-pentene/1-heptene proportion because of changes in crystallinity and in the polymorphs developed.

All these features seem to indicate that many questions are still open from a structural standpoint in these materials. Their response will obviously exert an important role in the resultant properties. It should be remarked the great importance of these materials because the control of the chain composition and microstructure makes possible to tailor the properties and allow production and processing of copolymers 
and/or terpolymers with supplementary behavior than that shown by iPP. The possibility of different ratios between the two comonomers makes that tailoring easier in the terpolymers. Consequently, different inherent characteristics can be modulated, which enable these materials suitable for specific applications. Thus, the aim of this investigation is to get a deeper insight of how crystalline details (mainly crystallinity and the existing polymorphs) affect the mechanical performance exhibited by propylene-co-1-pentene-co-1-hexene terpolymers synthesized in our laboratory. There are not much information of how replacing some of the 1-hexene counits for 1-pentene ones could affect viscoelastic or mechanical properties based on the expected changes in crystallinity and content of the trigonal form since the viscoelastic behavior was checked only once in the cPHe copolymers [18] and the mechanical response has been never reported in cPPe copolymers up to now. Figure S1 of Supporting Information

shows, however, different trends in variation of crystallinity with 1-pentene content in cPPe copolymers. Thus, knowledge of how these terpolymers behave can provide useful information to understand those differences. Dynamic mechanical thermal analysis and depth sensing indentation (DSI) measurements have been carried out. The former provides the knowledge of the viscoelastic response in a broad temperature interval while the latest are very useful to obtain knowledge about different aspects of the elastic, plastic and viscoelastic behavior of materials [36], including polymers [37]. These tests are, in addition, very appropriate for the characterization of polymers when one does not have much quantity (few grams) and the parameters estimated show a good correlation with those determined from other techniques. The corresponding results are discussed in terms of the structural features ascribed to the amorphous regions and the specific crystalline details.

\section{EXPERIMENTAL}

\section{Materials}

Random metallocene isotactic terpolymers based on propylene with 1-pentene and 1-hexene were synthesized in a broad range of compositions. Polymerizations were carried out in a stainless steel autoclave at $-5{ }^{\circ} \mathrm{C}$ with rac-dimethylsilylbis(1indenyl)zirconium dichloride/MAO as activated catalyst system. The specific details for the synthesis processes and microstructural features can be found in previous works [31,38]. Four different series of terpolymers (T4, T7, T10 and T14) and the corresponding homopolymer, iPP, were then prepared, each one with three different 1- 
pentene/1-hexene ratios: $75 \mathrm{Pe}: 25 \mathrm{He}, 50 \mathrm{Pe}: 50 \mathrm{He}$ and $25 \mathrm{Pe}: 75 \mathrm{He}$, referred as $75 \mathrm{Pe}-$ $25 \mathrm{He}, 50 \mathrm{Pe}-50 \mathrm{He}$ and $25 \mathrm{Pe}-75 \mathrm{He}$, respectively. Table 1 summarizes some of the characteristics of these terpolymers. Values of intrinsic viscosity are also included to provide information about molecular weight variation on composition. They were determined in decaline stabilized with Irganox $1010(1 \mathrm{~g} / \mathrm{L})$ at $135^{\circ} \mathrm{C}$.

Table 1. Comonomer content (total as well as in 1-pentene or 1-hexene), percentage molar ratio in the two comonomers, tacticity and intrinsic viscosity for the polymeric materials (polypropylene and terpolymers) under study.

\begin{tabular}{|c|c|c|c|c|c|c|c|}
\hline \multirow{2}{*}{ Sample } & \multicolumn{3}{|c|}{$\begin{array}{c}\text { Comonomer content } \\
(\mathrm{mol} \%)\end{array}$} & \multirow{2}{*}{$\% \mathrm{Pe}$} & \multirow{2}{*}{$\% \mathrm{He}$} & \multirow{2}{*}[\mathrm{mmmm}]{} & \multirow{2}{*}{$\begin{array}{c}{[\eta]} \\
(\mathrm{mL} / \mathrm{g})\end{array}$} \\
\hline & Total & $\mathrm{Pe}$ & $\mathrm{He}$ & & & & \\
\hline iPP & 0 & 0 & 0 & 0 & 0 & 90.3 & 98.0 \\
\hline $\mathrm{T} 4-75 \mathrm{Pe}-25 \mathrm{He}$ & 4.3 & 3.2 & 1.1 & 74 & 26 & 86.6 & 82.9 \\
\hline T4-50Pe-50He & 3.9 & 2.1 & 1.8 & 54 & 46 & 87.4 & 82.9 \\
\hline $\mathrm{T} 4-25 \mathrm{Pe}-75 \mathrm{He}$ & 3.7 & 0.9 & 2.8 & 24 & 76 & 90.2 & 86.1 \\
\hline $\mathrm{T} 7-75 \mathrm{Pe}-25 \mathrm{He}$ & 7.1 & 5.3 & 1.8 & 75 & 25 & 90.8 & 73.4 \\
\hline T7-50Pe-50He & 6.6 & 3.4 & 3.2 & 52 & 48 & 90.0 & 78.0 \\
\hline T7-25Pe-75He & 6.6 & 1.8 & 4.8 & 27 & 73 & 91.5 & 79.3 \\
\hline $\mathrm{T} 10-75 \mathrm{Pe}-25 \mathrm{He}$ & 10.3 & 7.9 & 2.4 & 77 & 23 & 87.3 & 62.2 \\
\hline $\mathrm{T} 10-50 \mathrm{Pe}-50 \mathrm{He}$ & 9.2 & 4.8 & 4.4 & 52 & 48 & 88.8 & 63.7 \\
\hline $\mathrm{T} 10-25 \mathrm{Pe}-75 \mathrm{He}$ & 9.6 & 2.9 & 6.7 & 30 & 70 & 88.1 & 68.4 \\
\hline $\mathrm{T} 14-75 \mathrm{Pe}-25 \mathrm{He}$ & 13.7 & 10.3 & 3.4 & 75 & 25 & 83.8 & 54.7 \\
\hline $\mathrm{T} 14-50 \mathrm{Pe}-50 \mathrm{He}$ & 14.4 & 7.2 & 7.2 & 50 & 50 & 82.6 & 53.1 \\
\hline $\mathrm{T} 14-25 \mathrm{Pe}-75 \mathrm{He}$ & 13.5 & 3.4 & 10.1 & 25 & 75 & 82.2 & 54.9 \\
\hline
\end{tabular}

\section{Film processing}

Films of the different terpolymers were attained by compression molding in a Collin press between hot plates (at a temperature of $30{ }^{\circ} \mathrm{C}$ above their melting point) using a pressure of $2.5 \mathrm{MPa}$ for $3 \mathrm{~min}$. Afterward, they were cooled down to room temperature under two different thermal treatments: the first one consisted of a relatively rapid cooling between plates refrigerated with cold water ( $\mathrm{Q}$ samples, using a cooling rate around $80-100{ }^{\circ} \mathrm{C} / \mathrm{min}$ ). The second one was a slow cooling process at the inherent cooling rate of the press by switching off the power (S samples, cooling rate 
around $0.5-1{ }^{\circ} \mathrm{C} / \mathrm{min}$ ). Pressure was maintained constant at $2.5 \mathrm{MPa}$ along both cooling treatments. The thickness of the resultant films ranged from 100 to $120 \mu \mathrm{m}$.

Terpolymers have been labeled as $\mathrm{T}$ followed by the total comonomer content (x) and the ratio of 1-pentene $(\mathrm{Pe})$ and 1-hexene $(\mathrm{He})$ counits $(\mathrm{Tx}-75 \mathrm{Pe}-25 \mathrm{He}, \mathrm{Tx}-50 \mathrm{Pe}-$ $50 \mathrm{He}$ and Tx-25Pe-75He). Names are, sometimes, shortened as T4, T7, T10 and T14 at a specific ratio in comonomers along the discussion and in Figures. Polypropylene homopolymer has been labeled as iPP or T0.

\section{Dynamic mechanical thermal analysis (DMTA)}

Viscoelastic relaxations were measured with a Polymer Laboratories MK II Dynamic Mechanical Thermal Analyzer, working in a tensile mode. The storage modulus, E', loss modulus, E", and the loss tangent, $\tan \delta$, of each solid sample were determined as function of temperature over the range from -150 to $125^{\circ} \mathrm{C}$ at fixed frequencies of $3,10,30$ and $50 \mathrm{~Hz}$, and at a heating rate of $1.5^{\circ} \mathrm{C} / \mathrm{min}$. For this analysis, strips of $2.2 \mathrm{~mm}$ wide and $15 \mathrm{~mm}$ length were cut from the molded sheets.

\section{Depth sensing indentation measurements}

Depth Sensing Indentation, DSI, experiments were performed at $20{ }^{\circ} \mathrm{C}$ with a Shimadzu tester (model DUH211S) equipped with a Berkovich type diamond indenter. At least 10 distinct indentations were performed in different regions of the surface for each and every one of the samples studied. The experimental protocol consisted in several stages: a) the application of a load of $10 \mathrm{mN}$ at a loading speed of $1.46 \mathrm{mN} / \mathrm{s}$; b) the maintenance of this constant load for $5 \mathrm{~s}$; and c) the release of the load at an unloading speed equal than the one used along the loading stage. Finally, indentation depth was registered, additionally, for $5 \mathrm{~s}$ after reaching the minimum load $(0.1 \mathrm{mN})$.

Hardness, $H_{i t}$, and reduced elastic modulus, $\mathrm{E}_{\mathrm{r}}$, have been initially evaluated from the load and depth indentation curves by using the Oliver and Pharr method [39]. This approach is effective to measure the elastic modulus and hardness of materials exhibiting elastic-plastic behavior, but may not be satisfactory in determining the properties of viscoelastic solids. Then, some corrections are occasionally required [40]. The Oliver and Pharr method was completely fulfilled under the experimental conditions here used and no correction has to be applied in these results.

Moreover, values of hardness [41] or indentation modulus [42,43] are not influenced by the substrate, since ratio of films thickness (ranging from 100 to $120 \mu \mathrm{m}$ ) 
to the maximum indentation depth (ranging from 1 to $4 \mu \mathrm{m}$ ) is greater than 30 for each and every of the samples.

\section{X-Ray Diffraction with Conventional and Synchrotron Radiation}

Conventional wide-angle X-ray diffraction patterns were recorded in the reflection mode by using a Bruker D8 Advance diffractometer provided with a Goebel mirror and a PSD Vantec detector (from Bruker, Madison, Wisconsin). $\mathrm{Cu} \mathrm{K} \alpha$ radiation $(\lambda=0.15418 \mathrm{~nm})$ was used, operating at $40 \mathrm{kV}$ and $40 \mathrm{~mA}$. The parallel beam optics was adjusted by a parabolic Göbel mirror with horizontal grazing incidence Soller slit of $0.12^{\circ}$ and $\mathrm{LiF}$ monochromator. The equipment was calibrated with different standards: $\mathrm{Al}_{2} \mathrm{O}_{3}$ (Corundum) and $\mathrm{Cr}_{2} \mathrm{O}_{3}$.

Real-time X-ray diffraction experiments (SAXS and WAXS) with synchrotron radiation have been performed on beamline BL11-NCD at ALBA (Cerdanyola del Vallès, Barcelona, Spain), at a fixed wavelength of $0.1 \mathrm{~nm}$. Two detectors have been used: a Rayonix LX255-HS detector for WAXS (with a pixel size of $40 \mu \mathrm{m}$ ), placed at about $19 \mathrm{~cm}$ from sample and a tilt angle of around 30 degrees, and an ADSC 210 detector for SAXS (with a pixel size of $102.4 \mu \mathrm{m}$ ), positioned approximately at $300 \mathrm{~cm}$ from the position of the sample. The temperature control unit was a Linkam hot stage, connected to a cooling system of liquid nitrogen. Some of the terpolymers have been analyzed after cooling from the melt in situ at different rates. The calibration of spacings was obtained by means of silver behenate and $\mathrm{Cr}_{2} \mathrm{O}_{3}$ standards. The initial 2D X-ray images were converted into 1D diffractograms, as function of the inverse scattering vector, $s=1 / d=2 \sin \theta / \lambda$. Film samples of around $5 \times 5 \times 0.1 \mathrm{~mm}$ were employed in the synchrotron analysis. These were covered by aluminum foil to ensure homogeneous heating or cooling and placed on the Linkam hot stage with Mica windows.

\section{RESULTS AND DISCUSSION}

As commented in the Introduction, tensile uniaxial tests were performed in propylene-pentene-hexene terpolymers for only one single total comonomers content, about $25 \mathrm{~mol} \%$, to investigate whether the deformation induced structural changes. Mechanical parameters, like Young's modulus or yield stress, were not estimated [30]. Consequently, this research will attempt to obtain additional knowledge about the mechanical response of these propylene-based derivatives. For that, the viscoelastic 
relaxations and storage modulus will be evaluated in a wide interval of temperature and indentation experiments will be performed at room temperature in poly(propylene-co-1pentene-co-hexene) terpolymers with distinct global comonomers content and with three comonomer ratios. As aforementioned, these indentation measurements enable determination of numerous parameters from few $\mu \mathrm{m}^{3}$ or even $\mathrm{nm}^{3}$. To fully understand the mechanical response, the structural features are described first, due to the influence that crystalline details have on the ultimate performance in polymeric materials.

Figure 1 shows the remarkable polymorphic behavior exhibited by these terpolymers. Four different ordered forms (monoclinic, orthorhombic, mesomorphic and trigonal lattices) are developed, depending upon overall composition, comonomer ratios and thermal history imposed.

It can be deduced that the fast cooled T4 terpolymers and the homopolymer only exhibit the diffractions that characterize the monoclinic $\alpha$ lattice whereas the S samples at that overall T4 composition and distinct ratios show additionally the (117) reflection from the orthorhombic cell. This fact is due to the much lower cooling rate used during processing of the $\mathrm{S}$ films. Thus, for the slowly cooled samples, coexistence of the monoclinic and orthorhombic forms is observed. Moreover, the relative $\alpha / \gamma$ ratio in the T4 terpolymers changes compared with that found in the homopolymer. The orthorhombic lattice [15] is the major polymorph in the slowly cooled T4 terpolymers while the monoclinic cell is the predominant one for the S iPP.

The Q samples in the T7 terpolymers display the development of a minor amount of defective monoclinic crystallites in addition to mesomorphic entities in a greater content, whereas the $\mathrm{S}$ specimens present an analogous polymorphic behavior to that observed in the T4 series, i.e., mainly orthorhombic crystallites coexisting with monoclinic ones in minority.

X-ray profiles for the rapidly cooled T10 terpolymers exhibit mesomorphic entities as unique ordered form. The $\mathrm{S}$ samples show, however, a more complex and more distinct structure. Three crystalline lattices are coexisting for the $\mathrm{T} 10-75 \mathrm{Pe}-25 \mathrm{He}$ terpolymer (trigonal, orthorhombic and monoclinic cells) while orthorhombic and monoclinic crystals are observed for the slowly crystallized T10-50Pe-50He and T10- 
$25 \mathrm{Pe}-75 \mathrm{He}$ specimens. The trigonal form is evident by the appearance of its characteristic diffraction at around $10.5^{\circ}$.

Q samples
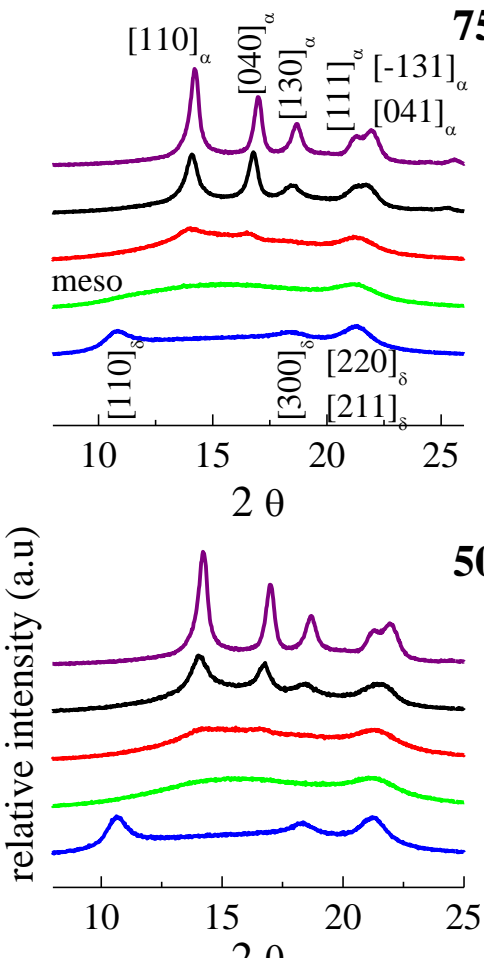

S samples

75Pe-25He

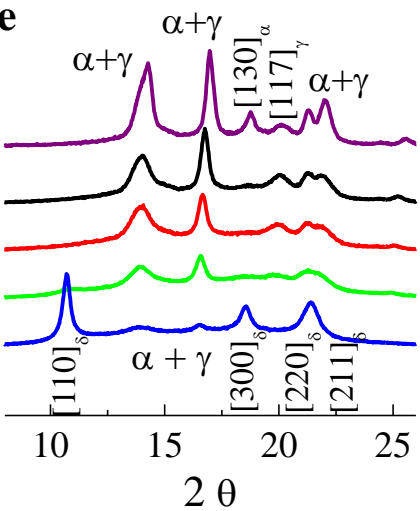

50Pe-50He

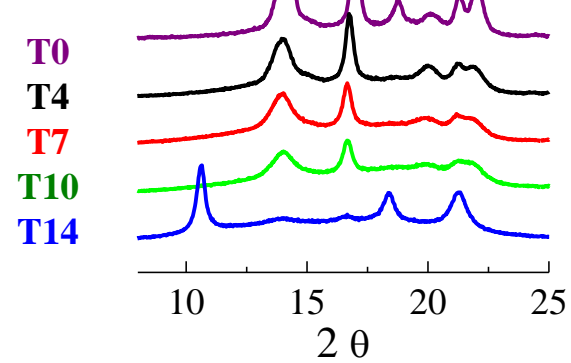

25Pe-75He

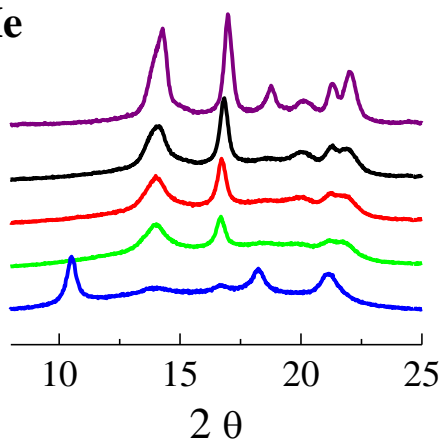

Figure 1. X-ray profiles for the different rapidly cooled (left) and slowly crystallized (right) samples at room temperature. The diffraction planes for the monoclinic and trigonal polymorphs have been added for a better comprehension.

Finally to the highest total composition T14, the trigonal polymorph competes with the mesomorphic phase in the Q samples and with monoclinic crystallites in the $\mathrm{S}$ specimens. This trigonal lattice appeared only, without coexisting with other polymorphs, at a content of $13.9 \mathrm{~mol} \%$ in slowly cooled iPHe copolymers [18] and of $14.7 \mathrm{~mol} \%$ in iPPe copolymers (there was no intermediate composition between 10.6 and $14.7 \mathrm{~mol} \%$ ) [27]. Then, global composition seems not to be high enough in these 
T14 terpolymers to be able to exclusively develop the trigonal polymorph, although its content is the majority (see Figure S2 of Supporting Information).

The overall X-ray degree of crystallinity, $f_{c}$, can be estimated from the diffractograms in Figure 1 following the procedure described before $[6,28,33]$, which has been briefly detailed in the Supporting Information. The so-obtained data are reported in Table 2 for all the specimens. Figure S2 of Supporting Information represents, as an example, the dependence with overall composition of the total crystallinity and the specific content from each polymorph in the Tx-75Pe-25He terpolymers for both thermal treatments.

Table 2. Crystallinity values and results from DSI measurements for isotactic polypropylene and terpolymers: $\mathrm{E}_{\mathrm{it}}$, indentation modulus, and $\mathrm{H}_{\mathrm{it}}$, indentation hardness.

\begin{tabular}{|c|c|c|c|c|c|c|}
\cline { 2 - 7 } \multicolumn{1}{c|}{} & \multicolumn{3}{c|}{ Q treatment } & \multicolumn{3}{c|}{ S treatment } \\
\hline Sample & $f_{c}$ & $\begin{array}{c}E_{i t} \\
\mathrm{MPa}\end{array}$ & $\begin{array}{c}H_{i t} \\
\mathrm{MPa}\end{array}$ & $f_{c}$ & $\begin{array}{c}E_{i t} \\
\mathrm{MPa}\end{array}$ & $\begin{array}{c}H_{i t} \\
\mathrm{MPa}\end{array}$ \\
\hline $\mathrm{iPP}$ & 0.59 & 2794 & 179 & 0.65 & 3151 & 185 \\
\hline $\mathrm{T} 4-75 \mathrm{Pe}-25 \mathrm{He}$ & 0.50 & 1223 & 82 & 0.56 & 1355 & 98 \\
$\mathrm{~T} 4-50 \mathrm{Pe}-50 \mathrm{He}$ & 0.48 & 1107 & 70 & 0.55 & 1231 & 81 \\
$\mathrm{~T} 4-25 \mathrm{Pe}-75 \mathrm{He}$ & 0.47 & 1043 & 67 & 0.54 & 1085 & 74 \\
\hline $\mathrm{T} 7-75 \mathrm{Pe}-25 \mathrm{He}$ & 0.35 & 606 & 47 & 0.46 & 690 & 54 \\
$\mathrm{~T} 7-50 \mathrm{Pe}-50 \mathrm{He}$ & 0.34 & 505 & 40 & 0.44 & 584 & 44 \\
$\mathrm{~T} 7-25 \mathrm{Pe}-75 \mathrm{He}$ & 0.35 & 497 & 37 & 0.43 & 534 & 44 \\
\hline $\mathrm{T} 10-75 \mathrm{Pe}-25 \mathrm{He}$ & 0.32 & 351 & 30 & 0.39 & 361 & 33 \\
$\mathrm{~T} 10-50 \mathrm{Pe}-50 \mathrm{He}$ & 0.31 & 376 & 31 & 0.38 & 339 & 31 \\
$\mathrm{~T} 10-25 \mathrm{Pe}-75 \mathrm{He}$ & 0.30 & 318 & 27 & 0.35 & 252 & 25 \\
\hline $\mathrm{T} 14-75 \mathrm{Pe}-25 \mathrm{He}$ & 0.39 & 425 & 35 & 0.47 & 448 & 41 \\
$\mathrm{~T} 14-50 \mathrm{Pe}-50 \mathrm{He}$ & 0.34 & 357 & 33 & 0.45 & 442 & 38 \\
$\mathrm{~T} 14-25 \mathrm{Pe}-75 \mathrm{He}$ & 0.37 & 309 & 26 & 0.42 & 320 & 28 \\
\hline
\end{tabular}

All of these results show a reduction of crystallinity with increasing the overall composition up to the T10 series whereas an unexpected increase occurs for the highest global content T14, as clearly deduced from Figure S2 and Table 2, which is associated with development of the trigonal polymorph. This finding indicates that a minimum in crystallinity is found for the T10 terpolymers. The subsequent rise is more evident in the 
slowly cooled samples than in the Q ones. This trend has been already observed in the iPPe copolymers slowly crystallized [35], as shown in Figure S1. The fact that T14 presents higher crystallinity values than the T10 series will be of considerable importance, as will be discussed below, for understanding dependences of several viscoelastic and mechanical magnitudes with respect to total comonomer composition. In addition, comparison between data for the cPPe copolymers depicted in Figure S1 [35] and those represented in Figure S2 related to these tPPeHe terpolymers allows deducing as main difference that the minimum in crystallinity is observed at around 8 mol\% in the cPPe copolymers while this minimum is found for the terpolymers at about $10 \mathrm{~mol} \%$. Thus, incorporation of 1-hexene affects the individual contributions of each polymorph and it is expected, consequently, that the mechanical properties are also influenced.

Cooling experiments performed within a broad range of scanning rates showed in these poly(propylene-co-1-pentene-co-1-hexene) terpolymers [44] the effects of the 1-pentene/1-hexene ratio on the enthalpy and on the crystallization and melting temperatures. The presence of 1-hexene slowed down the crystallization rate, all the more as higher was 1-hexene ratio in the terpolymer, which was in agreement with the observations in the iPPe and iPHe copolymers [20,26,30]. The influence of the amount in 1-hexene on the melting temperatures and the crystallinity was in the T14 series more pronounced than that found for inferior global contents. This agrees with the values listed in Table 2 for crystallinity. Melting temperatures are lowered as increasing 1hexene proportion in the terpolymer, i.e., comonomers ratio will affect not only the amount of crystallites but also their characteristics (size and perfection) and, consequently, the final mechanical performance. For instance, the ending melting temperatures for the T14 crystallized at $4{ }^{\circ} \mathrm{C} / \mathrm{min}$ were [31]: 86,79 and $75{ }^{\circ} \mathrm{C}$ in the $75 \mathrm{Pe}-25 \mathrm{He}, 50 \mathrm{Pe}-50 \mathrm{He}$ and $25 \mathrm{Pe}-75 \mathrm{He}$ samples, respectively. Differences in crystallinity for rapidly cooled specimens at the three comonomers ratios might be less important than for the slowly crystallized ones since in the former samples crystallization takes place under conditions very far from equilibrium and leads to rather thin and imperfect crystals. In the slowly cooled samples, the negative effect of 1hexene in the crystallinity and in the perfection of crystallites is more noticeable when the trigonal polymorph is developed, as seen in Figure S1 of Supporting Information. Then, $\mathrm{T}_{\mathrm{m}}$ and crystallinity differences between the iPPe and iPHe copolymers become 
greater at the highest compositions, where trigonal form appears. This fact is attributed to the kinetic differences found between 1-hexene and 1-pentene during formation of this $\delta$ lattice $[20,26,30,44]$.

To finish with the characteristics related to the ordered regions of these samples, it is interesting to remark that the Q treatment imposed to the T10 series (fast cooling from molten state at rate around $80{ }^{\circ} \mathrm{C} / \mathrm{min}$ ) actually leads to completely amorphous samples, i.e., no crystallization takes place initially during cooling, but the ordering appears by their stay at room temperature. Real-time temperature-variable $\mathrm{X}$ ray synchrotron experiments either at small angle (SAXS) or wide angle (WAXS) regions, depicted in Figure 2 for the T10-75Pe-25He terpolymer, corroborate that a cooling at 80 ${ }^{\circ} \mathrm{C} / \mathrm{min}$ from the melt leads to an amorphous state, as the initial profile monitored at -30 ${ }^{\circ} \mathrm{C}$ clearly shows, which is characterized by the lack of long spacing in SAXS and appearance of the amorphous halo in WAXS. On heating, the mesophase is formed by cold "crystallization" at around $0{ }^{\circ} \mathrm{C}$, which is "stable" at room temperature, what explains the fact of this mesophase being the ordered phase that is observed in the T10 Q films.

T10-75Pe-25He $\mathrm{f} 10 \mathrm{c} 80$
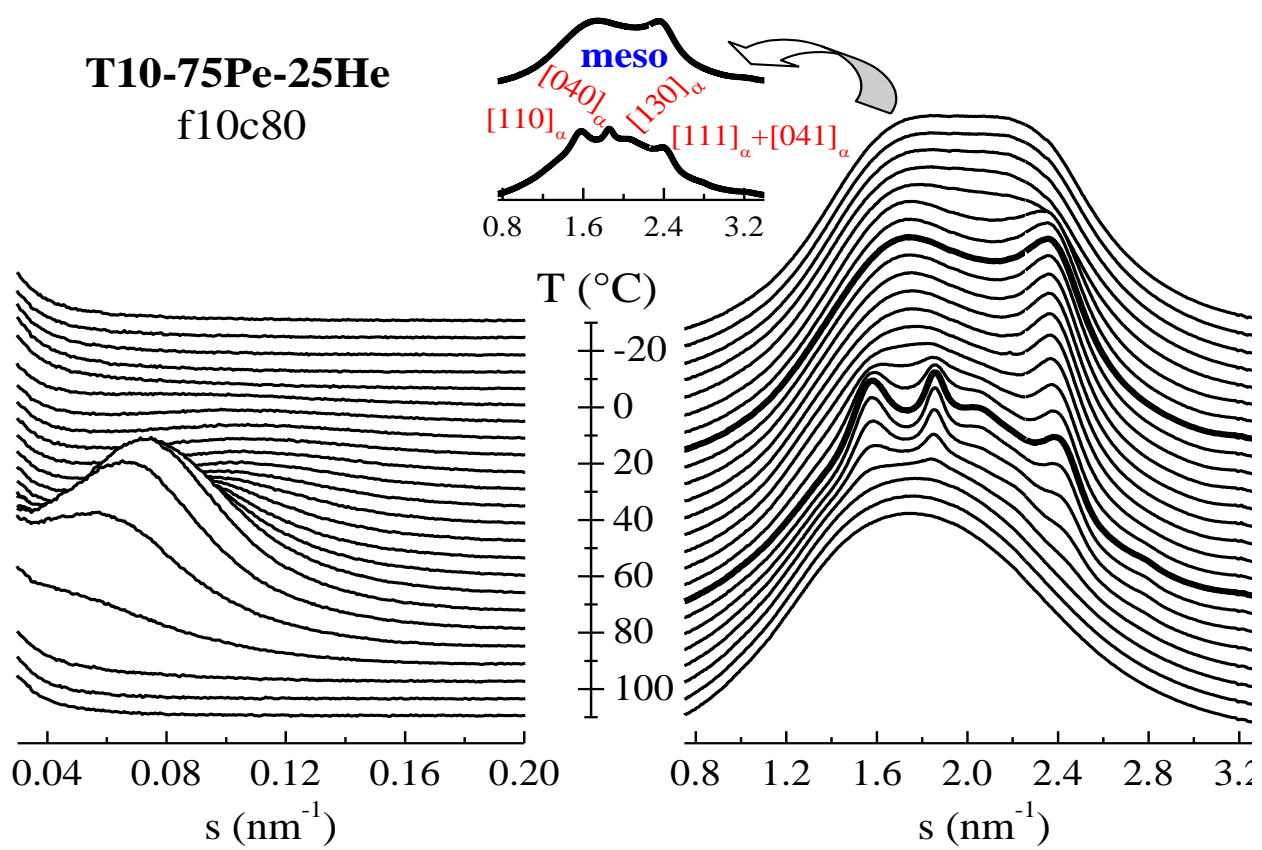

Figure 2. Synchrotron SAXS (left) and WAXS (right) 1D profiles for the melting at $10{ }^{\circ} \mathrm{C} / \mathrm{min}$ of the T10-75Pe-25He terpolymer just after its cooling from the melt at $80{ }^{\circ} \mathrm{C} / \mathrm{min}$. Thick lines in the WAXS profiles represent the pure mesomorphic entities and monoclinic crystallites, whose specific patterns have been depicted in the inset. For clarity, only one every three frames is plotted. 
This fact constitutes an important difference with the phase transitions reported in the cPPe copolymer with a comonomer content of $8 \mathrm{~mol} \%$ [6], which is the composition in which the minimum in crystallinity is observed. The real-time temperature-variable $X$ ray synchrotron experiments on cooling at a rate of $80{ }^{\circ} \mathrm{C} / \mathrm{min}$, lead to mesomorphic entities in that copolymer [6]. This feature indicates that the mesophase and the totally amorphous state are more easily obtained in the terpolymers. A comparison with cPHe copolymers cannot be established since no data are available.

On further heating, however, Figure 2 displays that this mesophase melts and recrystallizes (at about $55{ }^{\circ} \mathrm{C}$ ) into monoclinic crystals, and these crystallites melt finally at $100{ }^{\circ} \mathrm{C}$. The thorough DSC study about the influence of cooling rates on the crystalline forms able to be developed and their phase transitions perfectly agree with these results [44]. As shown there, the mesophase and even the totally amorphous samples can be readily obtained at easily accessible cooling rates for terpolymers T10 and T14.

Figure 3 presents the influence of total comonomers content and thermal treatment on the storage modulus $\left(E^{\prime}\right)$ and the loss tangent $(\tan \delta)$ as function of temperature. In Figure $3 \mathrm{a}$, results for the Tx-25Pe-75He series are shown. A decrease in the $\mathrm{E}^{\prime}$ values with temperature is observed in the homopolymer and the terpolymers at different global comonomers contents, as expected. The reduction of these $\mathrm{E}^{\prime}$ values is more significant at temperatures above the drop ascribed to the change in rigidity that takes place at the glass transition $\left(\mathrm{T}_{\mathrm{g}}\right)$. The existing differences in the crystalline characteristics between the terpolymers (like crystallinity and presence of distinct polymorphs) exert small effect at low temperatures, where mobility is almost frozen.

Moreover, the common effect of global composition on modulus is found in the fast cooled Tx-25Pe-75He terpolymers (Figure 3a top on the left), i.e., $\mathrm{E}^{\prime}$ values are lowered as content in comonomers increases in the whole temperature interval. This is the regular behavior described in copolymers $[22,24,45,46]$ and here it is seen in spite of crystallinity is higher in the Q sample T14-25Pe-75He than in the T10-25Pe-75He one. This fact seems to indicate that mesomorphic entities, although in a slightly smaller amount, involve a superior reinforcement than imperfect trigonal crystals (characterized by very broad and little intense diffractions, as seen in Figure 1) joined to a more 
defective mesomorphic polymorph [33]. Crystallites are rather thin due to the fast cooling applied and differences in amount are not too large to balance those from crystallite perfection.
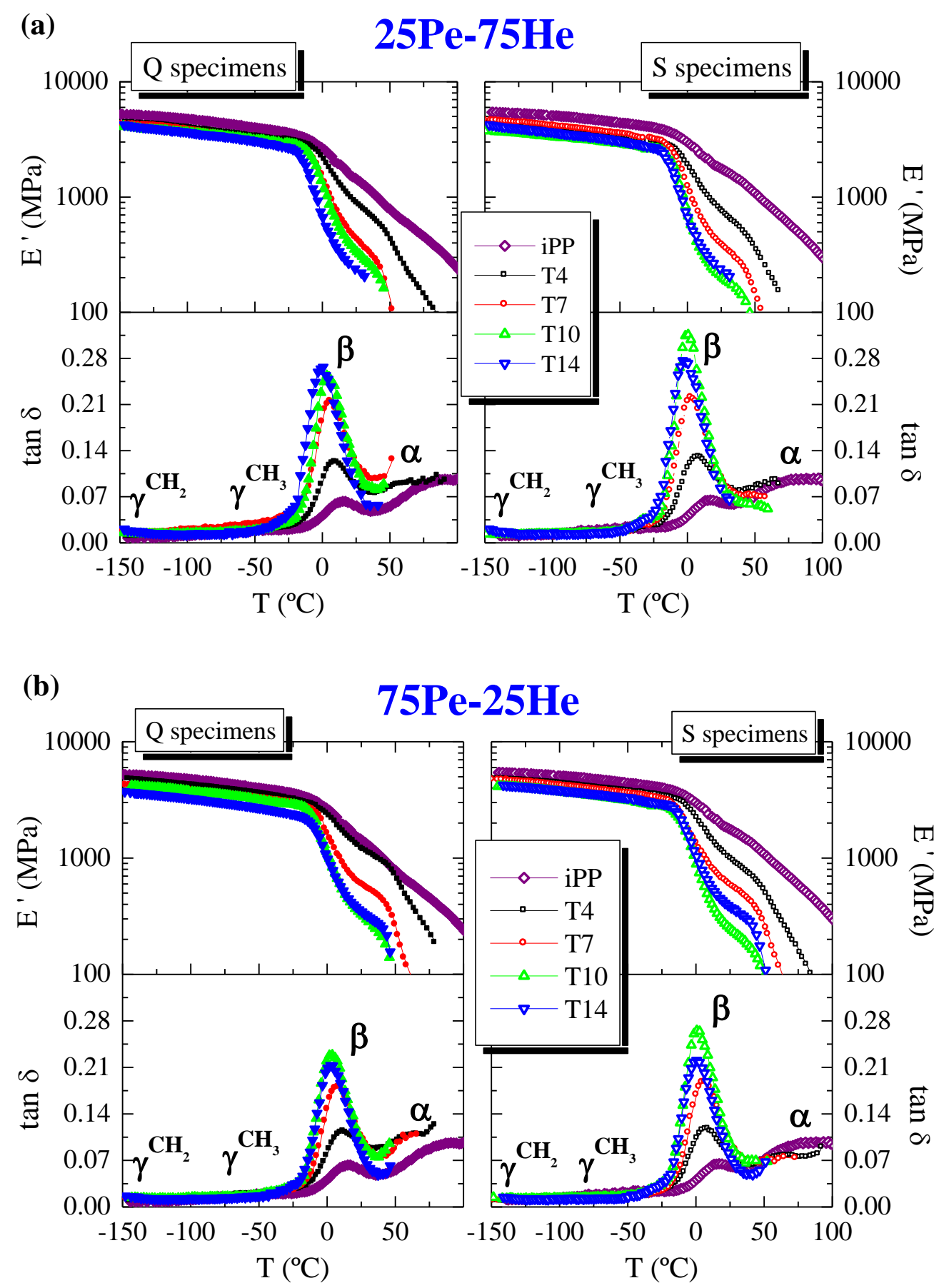

Figure 3. Temperature dependence of storage modulus and loss tangent $(\tan \delta)$ for iPP homopolymer and the different terpolymers at the $75 \mathrm{Pe}: 25 \mathrm{He}$ (a) and $25 \mathrm{Pe}: 75 \mathrm{He}$ (b) ratios and for the two thermal treatments. 
The dependence on global composition changes for the $\mathrm{S}$ thermal treatment at the highest comonomers content at temperature above the glass transition. Now, the slowly cooled T14-25Pe-75He specimen shows rather analogous $\mathrm{E}^{\prime}$ values than those found in the S T10-25Pe-75He sample. The monoclinic and orthorhombic crystallites existing in T10-25Pe-75He sample are less stiff than a combination of more imperfect monoclinic crystallites (in a small amount) together with trigonal crystals, in spite of crystals of the $\delta$ form are intrinsically more defective than those of the $\alpha$ lattice owing to the higher degree of inclusion of comonomeric units in the former crystallites [24]. The reduction in amount of monoclinic crystals is compensated by the formation of $\delta$ polymorph, becoming total crystallinity higher in the S T14-25Pe-75He specimen.

Looking at Figure 3b, the Q specimens Tx-75Pe-25He show a rather analogous behavior to this just described in the $\mathrm{S}$ Tx-25Pe-75He sample for the highest total contents, T10 and T14. Again, a rise in crystallinity is observed with total composition but now the thin trigonal crystals and defective mesomorphic polymorph from T14 lead to an $\mathrm{E}^{\prime}$ value similar to that presented by the corresponding $\mathrm{T} 10-75 \mathrm{Pe}-25 \mathrm{He}$ sample. The response is somehow different in the S Tx-75Pe-25He samples, since the values of storage modulus become in the T14 sample clearly higher than those in the T10 one at temperatures above $10{ }^{\circ} \mathrm{C}$. The monoclinic/orthorhombic crystals (in addition to a very small amount of $\delta$ crystallites, as indicates the presence of a small shoulder at about $10^{\circ}$ in $2 \theta$ in Figure 1) involve in the S T10-75Pe-25He sample less reinforcement and, consequently, smaller stiffness than a combination of well developed trigonal crystals and a small amount of imperfect monoclinic crystallites. This unusual dependence of $\mathrm{E}^{\prime}$ on total composition must then be understood by considering the total crystallinity, relative amount of each polymorph in a given sample, size and perfection of the existing crystallites, the main variable being the overall crystallinity.

Figure 4 displays additional differences between the responses found at the different comonomers ratios for the two thermal treatments. The decrease in $\mathrm{E}^{\prime}$ as increasing 1-hexene independently of thermal history applied during processing is associated with the fact that the crystallinity is usually reduced and crystalline details are worsened as 1-hexene is raised in the ratio of these terpolymers (see Table 2 and Figure 1). These features corroborate the decrease in the melting temperatures [44] found in these terpolymers at a given cooling rate as increasing 1-hexene content, being 
more important as global contents were raised [44]. These variations in crystallinity and melting temperatures were also evident when compared iPPe with iPHe copolymers, mainly at the highest compositions where trigonal form is developed [20,24,26].
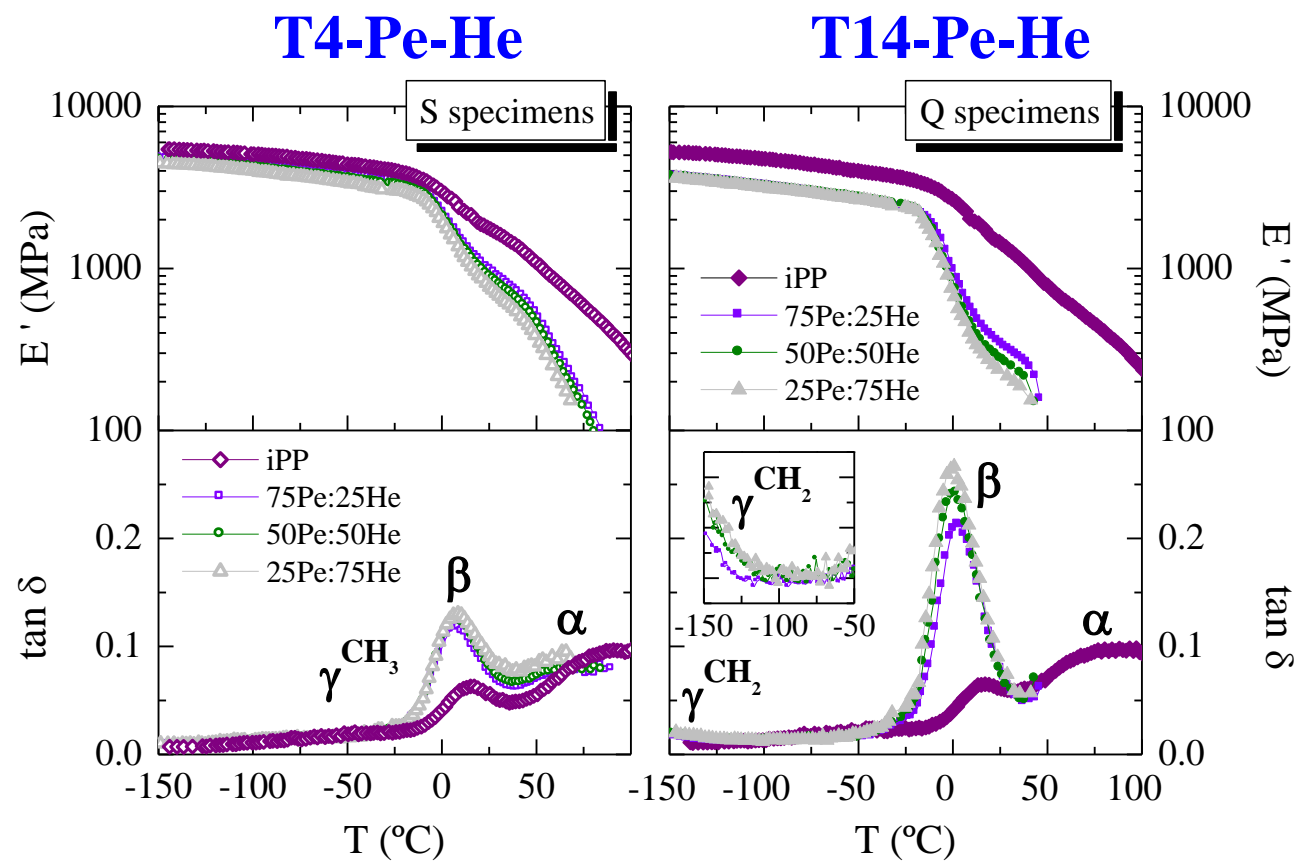

Figure 4. Temperature dependence of storage modulus and loss tangent $(\tan \delta)$ for iPP homopolymer and two series of the terpolymers: T4 slowly crystallized (left) and T14 rapidly cooled specimens (right), at the three comonomers ratios.

DMTA also provides information about loss magnitudes, i.e., loss modulus and loss tangent, which are associated with the part of energy dissipated along any molecular motion and to the mechanical damping, respectively. These two magnitudes allow learning about the relaxation mechanisms that can take place at a given temperature range. The dynamic mechanical spectrum of iPP in the solid state as a function of temperature is well-known [47,48]. iPP exhibits three relaxation mechanisms, labeled as $\gamma, \beta$ and $\alpha$ in order of increasing temperature. The molecular cause behind each process corresponds to the local motions (methyl rotation around backbone) in the amorphous regions, the glass transition and movements within the iPP crystalline regions, respectively.

The several relaxations that take place within this temperature interval for some of these terpolymers are displayed in the plots of $\tan \delta$ in either Figure 3 or 4 . As noticeably observed, the location and width of these mechanisms are considerably 
dependent on total content in counits, ratio of comonomers and crystalline features. Accordingly, the $\alpha$ relaxation, appearing at the highest temperature and related to motions within the crystalline phase especially to defect diffusion [49], is only clearly evident, besides the iPP homopolymer, in the T4 terpolymers, i.e., those with a global content of around $4 \mathrm{~mol} \%$. The incorporation of either 1-pentene or 1-hexene involves significant changes in the crystalline characteristics exhibited by these samples: reduction in crystallinity, development of different polymorphs, as well as variation in crystal size. All these factors lead to a shift of this process to lower temperatures since motions can take place just above glass transition. This relaxation, then, becomes completely overlapped in $\tan \delta$ (and also in the $\mathrm{E} "$ representation, not shown) to the $\beta$ process as comonomer content further increases. In fact, it turns out more evident from the $\mathrm{E}^{\prime}$ representation.

The $\beta$ relaxation appears at around $15^{\circ} \mathrm{C}$ in the homopolymer $(\tan \delta$ plot), i.e. at temperatures below the viscoelastic process ascribed to the movements in the crystalline regions. The $\beta$ relaxation is related to global motions of long chain segments that occur within the amorphous regions during the glass transition. Thus, a cooperative movement is behind the great drop in the $\mathrm{E}^{\prime}$ magnitude found at this temperature range (see Figures 3 and 4). The results from a detailed analysis of this relaxation are presented in Figure 5.

The upper plots in this Figure show that the $\tan \delta$ intensity raises significantly as comonomers content increases in the terpolymers up to the T10 series because of the increase in their amorphous fraction and, consequently, reduction in crystallinity involving a larger capability of motions within the amorphous regions. On the contrary, intensity remains constant or even is reduced for the T14 terpolymers. This feature is associated with the further increase of crystallinity due to development of the trigonal form at that highest overall content. This dependence on total composition (an almost constant value or presence of a maximum value of intensity at about the T10 global content) exhibited by these terpolymers was not found in the iPHe copolymers [18], where a continuous increase of intensity was observed with the comonomer content. This fact was related to the progressive decrease in crystallinity observed in those iPHe copolymers in the whole range of compositions. 

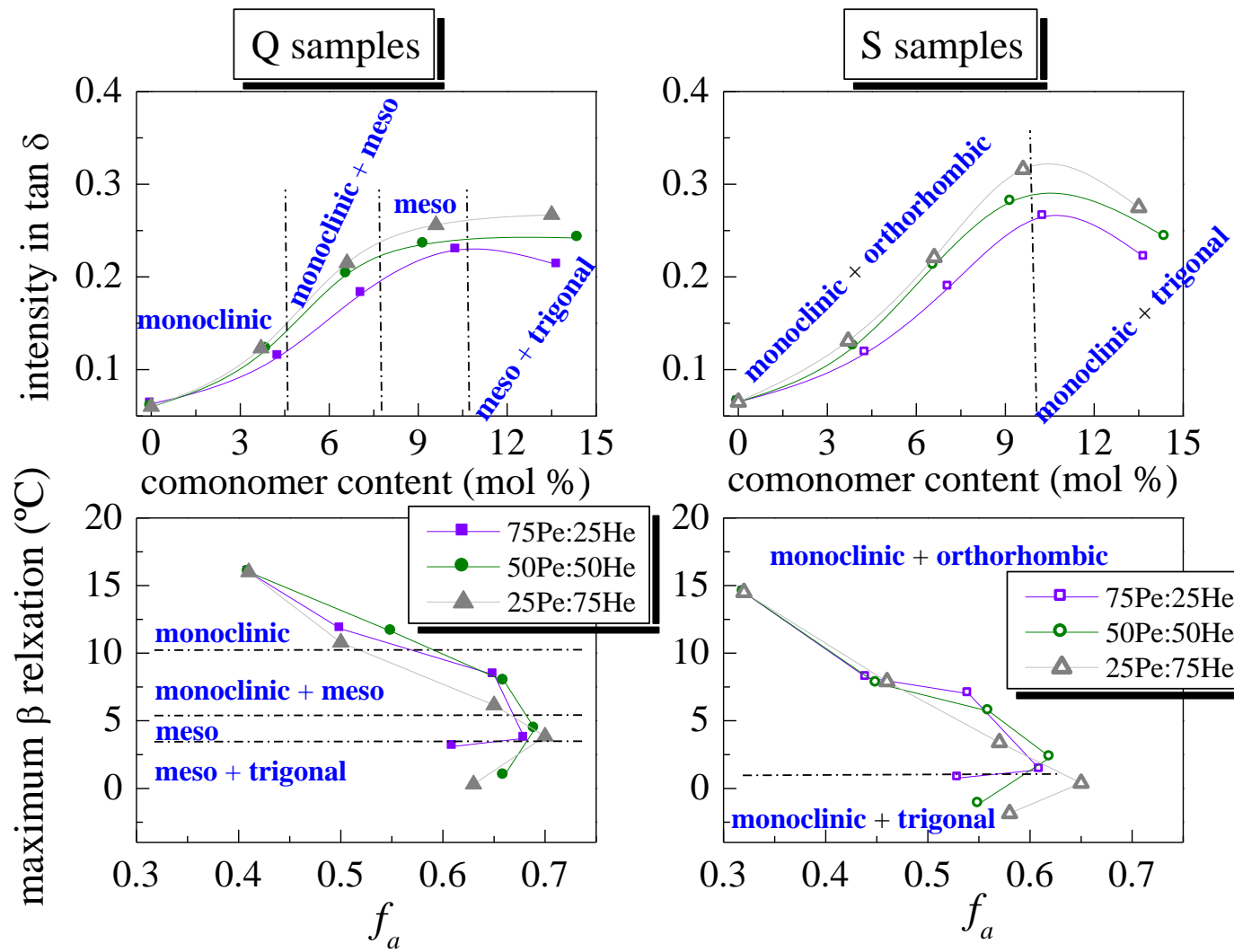

comonomer content $(\mathrm{mol} \%)$

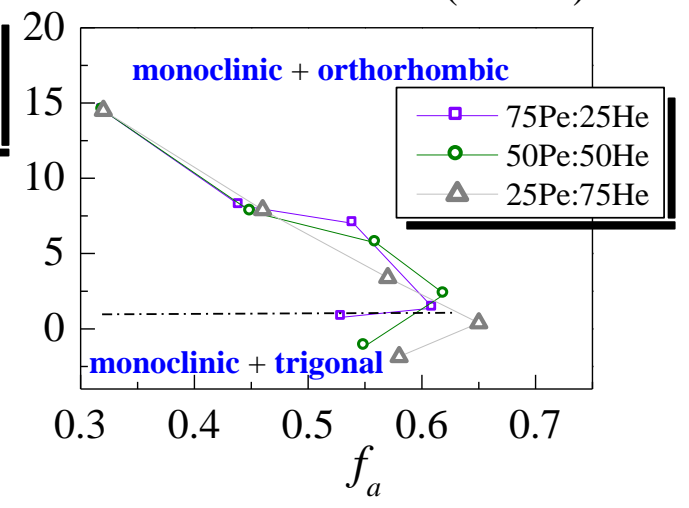

Figure 5. Dependence of intensity with global comonomers content (upper plots) and of temperature location with the amorphous fraction, $f_{a}$, (lower plots) for the $\beta$ relaxation at both thermal histories evaluated.

It is also remarkable that, in general, intensity of $\beta$ relaxation in the $S$ samples is slightly higher than that in the Q specimens in spite of crystallinity values (see Table 2) are superior in the $\mathrm{S}$ ones, mainly in the T10 series. This feature was previously described for propylene copolymers with 1-hexene at low and intermediate contents in comonomer [45]. It was assumed that presence of $\gamma$ crystallites in the slowly cooled specimens reduced hindrance to motion within the amorphous regions and, thus, intensity rose.

Location of the $\beta$ relaxation also changes with global composition, moving to lower temperatures as increasing comonomers content, as represented in the bottom plots of Figure 5. Cooperative motions can occur easily when amount of amorphous fraction, $f_{a}$, increases, independently of their nature. The development of trigonal form clearly changes the dependence on amorphous content since $f_{a}$ is reduced at those samples of T14 series. The $\beta$ relaxation is shifted to lower temperature in the T14 
terpolymers in spite of their higher crystallinity values. This could be ascribed to an increase in the free volume because of the highest amount of side branches.

Figure 5 also shows that comonomers ratio at a given overall content also appears to affect cooperative motion capability within the amorphous regions. This mobility is facilitated as 1-hexene content is raised. Thus, intensity is the highest and location of temperature the lowest one for terpolymers of the Tx-25Pe-75He series. A superior amount of 1-hexene leads to thinner crystals, independently of their nature, as has been demonstrated by their lower melting temperature when developed at similar cooling rates $[31,44]$.

The other $\gamma^{\mathrm{CH}_{3}}$ relaxation process ascribed to rotational motions of methyl groups is only clearly observed in the T4 terpolymers at temperatures slightly lower than in the polypropylene homopolymer. Its intensity is reduced at that composition and this rotation of methyl groups can take place at lower temperatures for higher contents. Thus, it seems to merge with other process appearing in the T10 and T14 terpolymers. This overlapped relaxation has been already described at around $-150{ }^{\circ} \mathrm{C}$ in other propylene based copolymers with intermediate and high comonomer contents of several counits in alpha-olefins [46,50]. It has been named as $\gamma^{\mathrm{CH}_{2}}$ because its molecular origin is related to the joint movements of chains containing three or more methylene units, i.e., its inherent cause is analogous to that responsible for the typical $\gamma$ relaxation observed in polyethylene [51,52] (although these methylene groups are located now in the side chains). Therefore, its intensity is dependent upon content in counit since a higher amount of methylene groups can participate in this motion as comonomer content increases.

Figure 6 depicts the loading-maintenance-unloading processes from DSI experiments for the samples $\mathrm{Tx}-50 \mathrm{Pe}-50 \mathrm{He}$ at the two thermal treatments analyzed. Important changes are observed depending on global composition in comonomers, both on the shape of curves and on the indentation depth reached. The iPP homopolymer is the hardest material, and, consequently, the indenter cannot penetrate too much in its surface and the depth at the end of first stage is the smallest. 


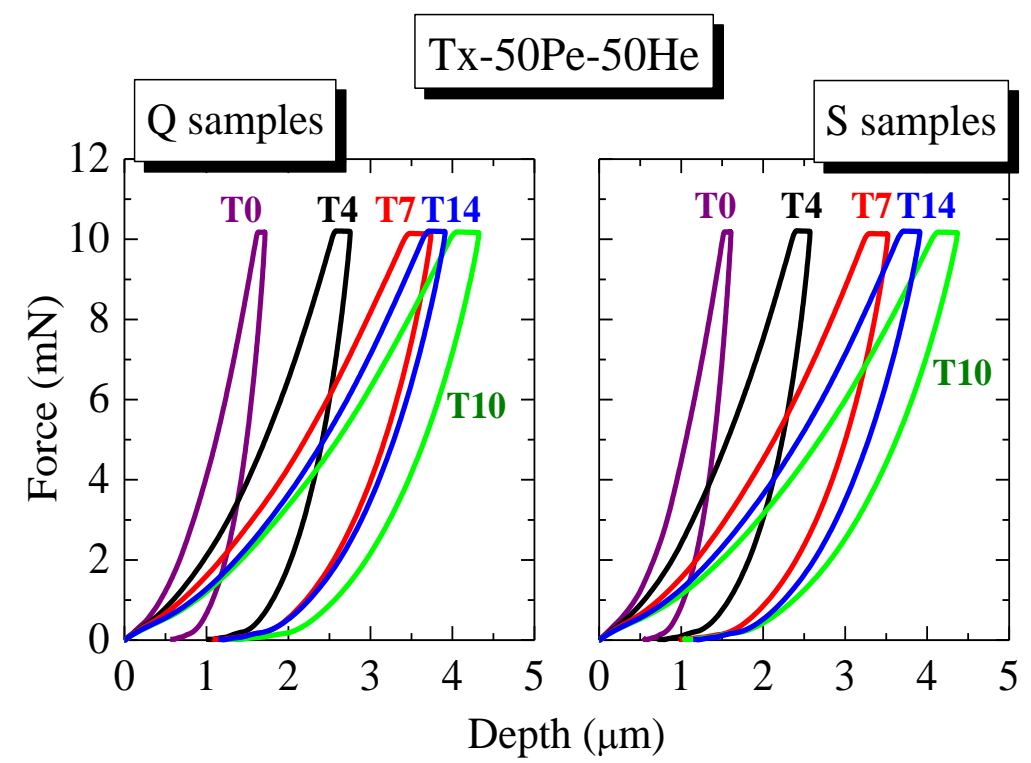

Figure 6. Load-indentation depth curves for the isotactic polypropylene (T0) and terpolymers Tx-50Pe-50He for both thermal treatments.

Terpolymers become progressively softer and depth is enlarged since crystallinity decreases as the overall comonomers content is increased except for the T14 series (see Table 2). At this highest global content, as aforementioned, a rise in crystallinity occurs because the trigonal polymorph can now be developed, coexisting with either mesomorphic entities in the $\mathrm{Q}$ samples or with monoclinic crystals for the $\mathrm{S}$ specimens (see Figure 1). This increase in crystallinity exhibited by this T14 family leads to an enlargement in the elastic modulus and in hardness values determined at room temperature from these indentation measurements (see $\mathrm{E}_{\mathrm{it}}$ and $\mathrm{H}_{\mathrm{it}}$ values in Table 2). Their dependence on global composition is represented in Figure 7. The trend observed up to $10 \mathrm{~mol} \%$ is similar to that seen in other copolymers $[33,45,46,53,54]$. On the contrary, the tendency is completely unusual for the highest content, i.e., in the T14 series. The behavior in the T14-75Pe-25He and T14-50Pe-50He terpolymers is quite analogous to that found for the Young's modulus estimated from stress-strain tests on propylene-co-1-pentene-co-1-heptene terpolymers rapidly cooled, at ratios and total compositions similar [32]. It was associated with the increase in crystallinity because formation of the trigonal form. In contrast, the modulus values and crystallinity showed a decreasing trend with increasing comonomer content in iPHe copolymers [22,24]. This continuous reduction in crystallinity has been also described in iPPe copolymers [26] although mechanical parameters have not been reported yet in literature. 


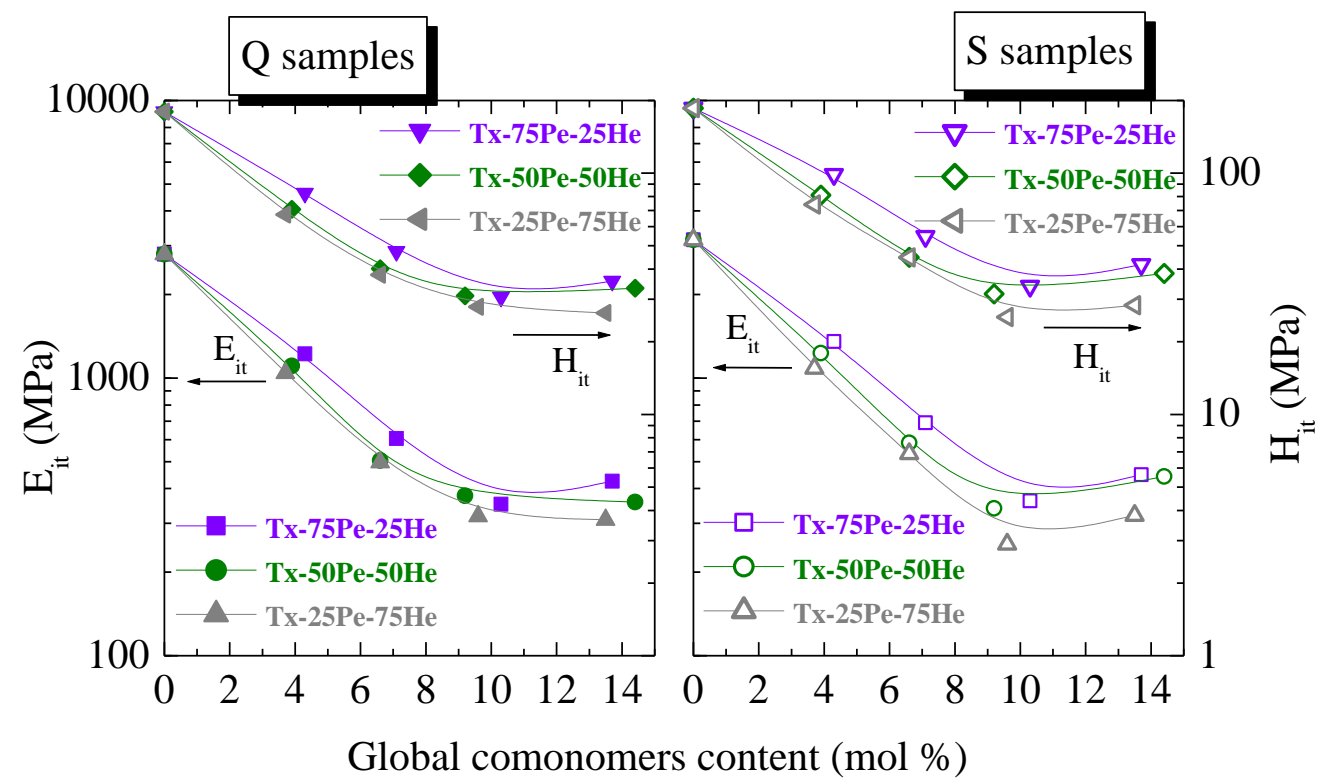

Figure 7. Dependence on global content in comonomers of indentation modulus (left axis) and hardness (right axis) for isotactic polypropylene and the terpolymers at the different comonomers compositions and ratios.

Development of the trigonal $\delta$ crystallites provokes, then, the increase in crystallinity, being more significant in the slowly cooled specimens because thicker crystals can be generated compared with those much thinner ones formed during a fast cooling. Accordingly, the rise in the mechanical parameters related to rigidity is more important in the $\mathrm{S}$ samples. Comonomers ratio seems to be also relevant at a given overall content. Thus, stiffness is seen to be slightly reduced as 1-hexene content increases in these terpolymers. This can be ascribed to crystallinity, which is usually lowered in the terpolymers with the highest 1-hexene ratio; and as well, to the smaller crystals found in the Tx-25Pe-75He terpolymers, as proved by their lower melting temperatures $[31,44]$.

Figure 8 displays the variation of indenter depth with time in the iPP and Tx$25 \mathrm{Pe}-75 \mathrm{He}$ samples for the two thermal treatments. The depth reached at the end of loading period, at around $7.5 \mathrm{~s}$, is clearly dependent on global composition and thermal history. The most remarkable variation is that observed again between the T10 and T14 series. A very similar depth is reached in the T10-25Pe-75He and T14-25Pe-75He samples rapidly cooled while that depth is larger in the T10-25Pe-75He slowly cooled than in its S homologous T14-25Pe-75He. 


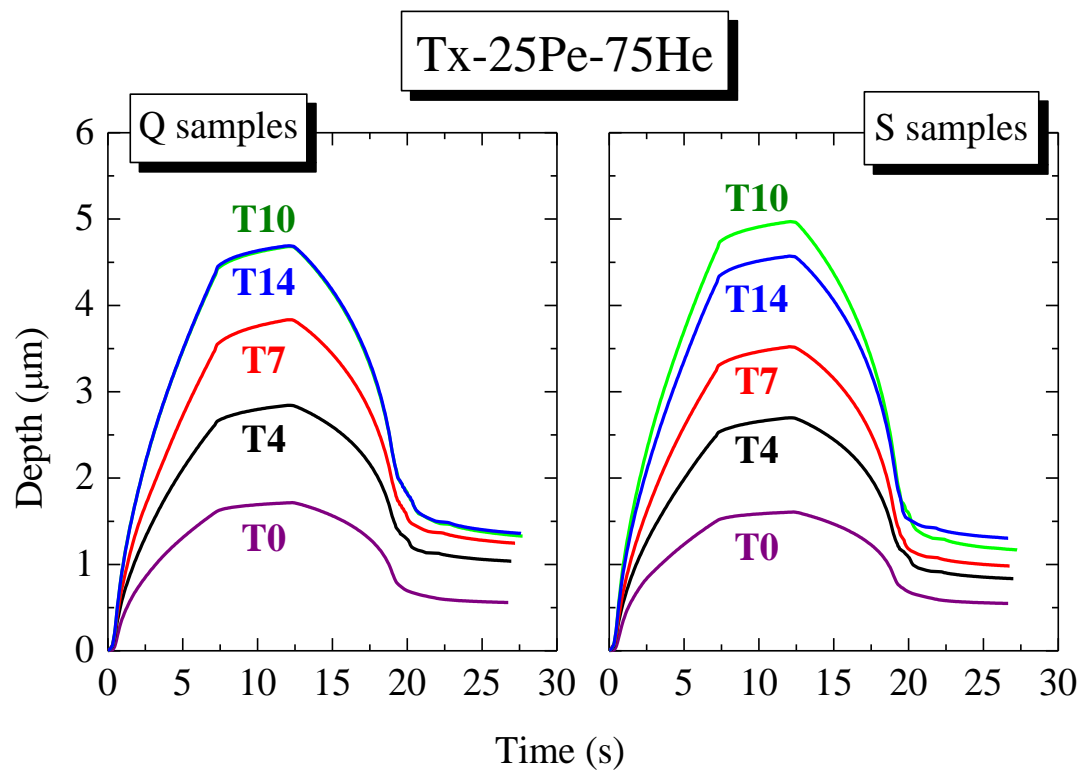

Figure 8. Indenter depth dependence on time for isotactic polypropylene and the different Tx-

$25 \mathrm{Pe}-75 \mathrm{He}$ terpolymers at the two thermal treatments $(\mathrm{Q}$, on the left, and $\mathrm{S}$, on the right).

The increase in crystallinity because of the trigonal crystals in the T14 series avoids their softening with respect to that shown by the T10 series. This effect is more evident in the slowly cooled specimens than in the rapidly ones because trigonal crystals are more in amount (see Figure S2 in the Supporting Information representing results for the Tx-75Pe-25He series taken as example) and are thicker in the S sample T14$25 \mathrm{Pe}-75 \mathrm{He}$ since crystallization has occurred under more favorable conditions than for Q T14-25Pe-75He specimen.

It can be also deduced from Figure 8 that the unloading process is mainly dominated by the viscoelastic recovery of the different materials. Once experiment is over, a permanent deformation (plus a small amount of delayed elastic recovery) is observed in all the specimens since they are not purely elastic. The softening process involves a rise in the amount of the plastic deformation as global composition increases. Presence of the trigonal form is again important, the values of permanent deformation being similar for Q samples in the T10 and T14 series and only slightly superior in the slowly cooled T14 specimens. These differences are associated with the fact that monoclinic crystals coexist with thicker trigonal crystallites in the S samples while the mesomorphic form is the one competing with thinner $\delta$ crystals in the $\mathrm{Q}$ specimens. 
These DSI experiments provide also information on the creep response of the different terpolymers during the time that load is maintained constant in between the loading and unloading stages. These creep tests have significant potential for interpreting the mechanical responses in polymers because their inherent response always includes a time dependent deformation. Therefore, a study related to the creep has been performed for some of these terpolymers. Changes of indentation depth at constant load take place at times ranging around 7.5 and 12.5 seconds (see experimental section). Then, determination of $h_{\max }-h_{1}\left(h_{\max }\right.$ and $h_{1}$ being final and initial depth during the creep stage, respectively) from data of Figure 8 is carried out to explore some aspects of this time dependent mechanical response. Kinetics of the indentation during the holding period at maximum load is considered to be related to creep while the delayed elastic recovery, DER, controls the rising movement of the indenter during the final holding period. Several phenomenological models have been suggested to describe the kinetics of these phenomena [55-57]. Among others, Kohlrausch-Williams-Watts, KWW, relaxation function [58] has been selected to analyze these results because it has been proved that this function can be used satisfactorily for describing the relaxation processes in different kind of polymeric and non-polymeric materials [59]. This decay function provides a very precise description of the experimental data despite number of unknown parameters is relatively reduced in the KWW model. Thus, it can be applied to systems with either a unique relaxation time or a relaxation time distribution upon several time decades.

Movement of indenter under the action of maximum load can be phenomenologically described by means of the following KWW stretched exponential function:

$$
h\left(t_{c r}\right)=h_{0}+\Delta h\left(1-\exp \left(-\left(t_{c r} / \tau\right)^{\beta}\right)\right)
$$

where $t_{c r}$ reads for the time elapsed since the beginning of the holding period; $h_{0}$ for the penetration depth when $t_{c r}=0 ; \Delta h$ for the extrapolated displacement of the indenter for a very large load holding time; $\tau$, for the effective retardation time; and, $\beta$ for the stretching exponent $(0<\beta \leq 1)$. Figure 9 shows that this relaxation function [1] yields an accurate description of the indentation depth variation during the holding period for these DSI experiments. 
In order to compare the behavior of the different terpolymers, a kind of indentation pseudo-compliance is defined by:

$$
J_{i t}^{*}\left(t_{c r}\right)=\frac{\left(h\left(t_{c r}\right)-h_{0}\right) / h_{0}}{H M s}
$$

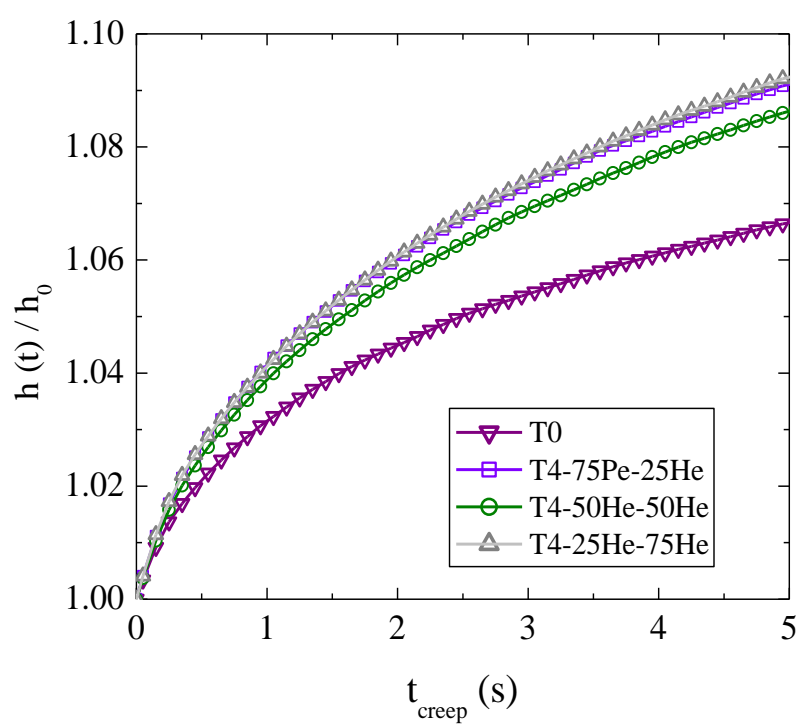

Figure 9. Creep behavior for iPP and for the $\mathrm{T} 4$ series at the different comonomers ratios as a function of the time (open symbols: experimental results, line: fitting of data by equation [1])

This description parallels the one of compliance, which is the viscoelastic function that can be obtained from creep experiments. Now, deformation has been substituted by the relative depth increment and stress replaced by the Martens hardness that equals the mean contact pressure exerted by the indenter.

Left plot in Figure 10 depicts the dependence upon overall comonomers composition of $J_{i t}^{*}(\infty)$ at the three comonomers ratios for the $\mathrm{S}$ samples, while right plot of Figure 10 represents the variation with the thermal history for the Tx-75Pe-25He terpolymers at the distinct global contents. The former one shows that the terpolymers become more compliant as the global content increases up to $10 \mathrm{~mol} \%$, composition at which pseudo-compliance reaches a maximum value. This figure also shows that $J^{*}{ }_{i t}(\infty)$ is not independent of the nature of the comonomers: the Tx-25Pe-75He terpolymers creep more easily than the Tx-75Pe-25He and Tx-50Pe-50He ones at the same total content in comonomers. The influence of presence of 1-hexene units is again noticeable. A highest ratio in 1-hexene triggers a slight diminishment in crystallinity and in crystallites perfection, since these longer lateral chains are more difficult to be 
accommodated in the crystalline regions. This affects the global mobility (see Figure 5) and, therefore, the deformability of the resultant terpolymers.
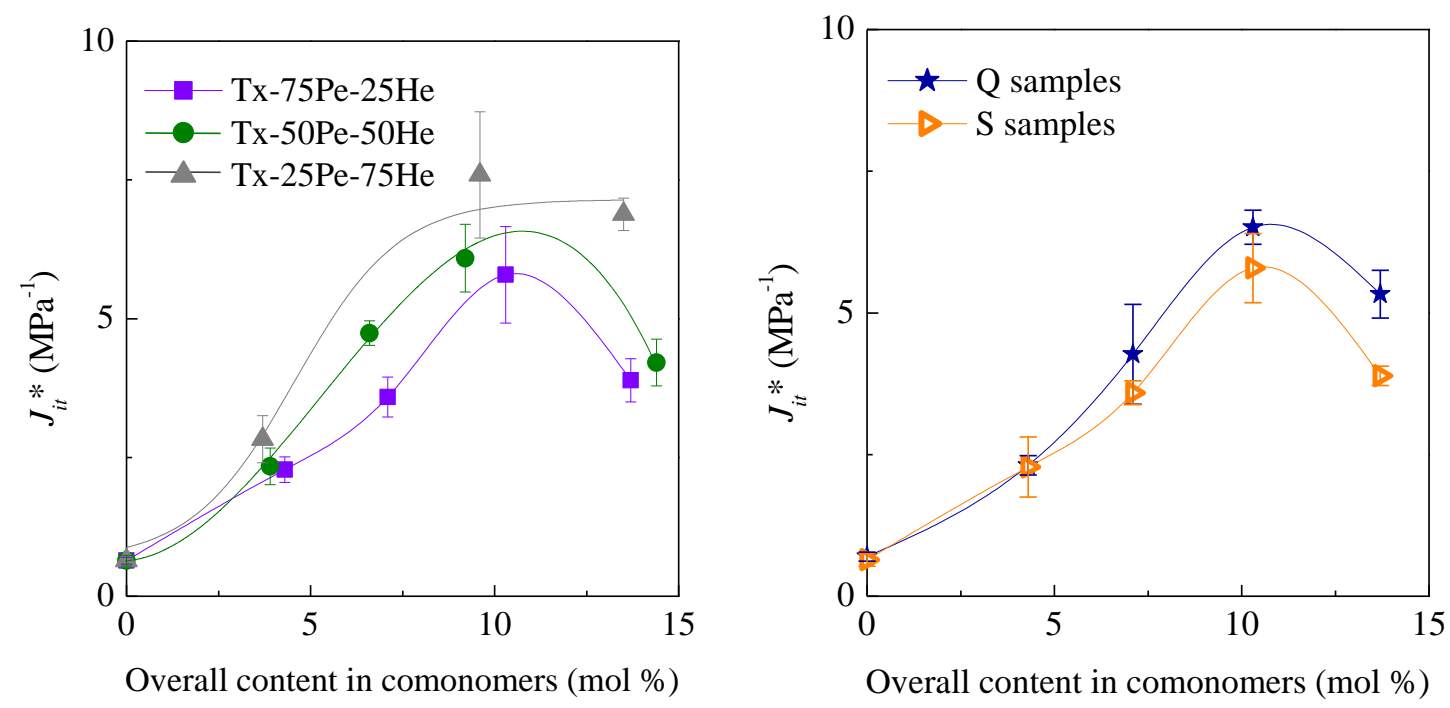

Figure 10: Variation of asymptotic value of the indentation pseudo-compliance, $J_{i t}{ }^{*}$, with the global composition of the terpolymers at different comonomers ratio in the $\mathrm{S}$ samples (left) and at the two thermal histories for specimens with the $75 \mathrm{Pe}-25 \mathrm{He}$ ratio (right).

Plot on the right in Figure 10 seems to suggest that terpolymers processed by a fast cooling are materials more complaint than those slowly crystallized from the melt at same composition. Considering that modulus and compliance are related, all these results can be explained in terms of the existing variations in the crystalline characteristics between samples obtained by these two thermal histories, already discussed previously. Consequently, Figure 10 confirms the great effect of crystallinity, competition between polymorphs and their relative proportions as well as crystallite perfection on the rigidity and deformability of these terpolymers.

It is also interesting to discuss the effect of composition and of thermal history on the rate of indentation under the action of a constant load in these terpolymers. Since KWW function is characterized by a retardation time distribution, the decay rate can be assumed to be inversely proportional to the mean retardation time, $\langle\tau\rangle$, which can be expressed as: 


$$
<\tau>=\frac{\tau}{\beta} \Gamma\left(\frac{1}{\beta}\right)
$$

where $\Gamma$ represents the Euler gamma function. The fitting of the experimental data of the terpolymers to $\mathrm{KWW}$ function shows that $\beta$ exponent neither depends on composition nor on thermal history $(\beta=0.72 \pm 0.02)$. Then, the average indentation rate for the load holding period can be related to $\tau$.

Figure 11 displays the variation of effective retardation time with composition for the rapidly cooled specimens and suggests that creep is accelerated as the overall content in comonomers increases. This behavior seems to indicate that the macromolecular chains become more mobile due to the incorporation of the counits, either 1-pentene or 1-hexene, corroborating the results represented in Figure 5 for the relaxation associated with the glass transition.

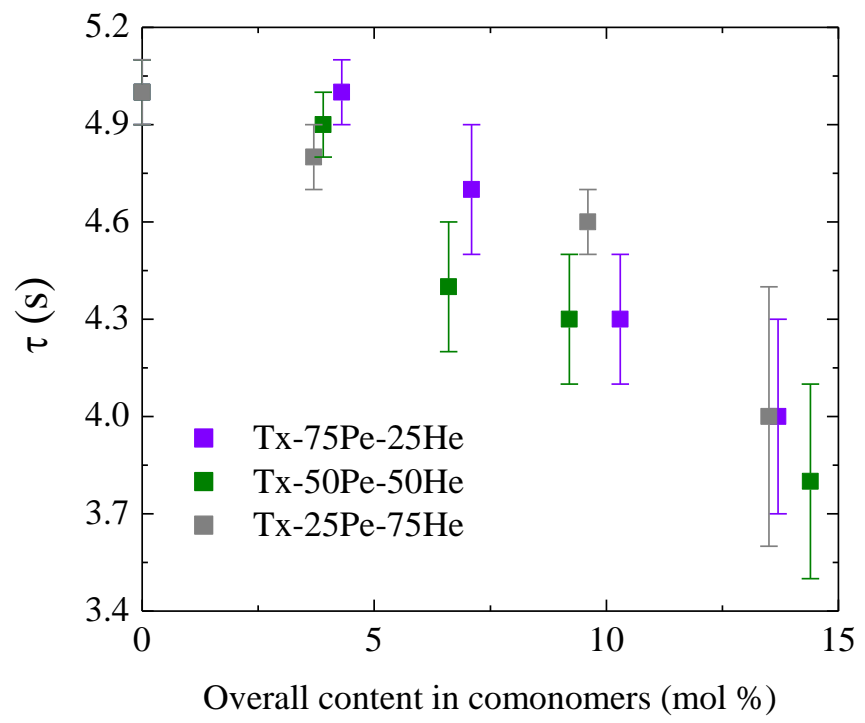

Figure 11. Dependence of the effective retardation time, $\tau$, on the overall content in counits for the quenched samples.

It is also noticeable that the dependence of $\tau$ on the global content in comonomers shows a decreasing trend and does not exhibit any maximum or minimum for the T10 series, differently to what has been observed for diverse parameters in these terpolymers. This result seems to indicate that, in these rapidly crystallized terpolymers, the influence with indentation rate of the increment of chain flexibility ascribed to the incorporation of the comonomers predominates over that of the tying effect associated 
with the increasing degree of crystallinity at the highest comonomers contents. It should be said that this downward tendency is found in these samples with more defective crystalline characteristics and, consequently, with reduced stiffness and higher mobility.

\section{CONCLUSIONS}

Four different ordered forms: monoclinic, orthorhombic, mesomorphic and trigonal, depending upon overall composition, comonomer ratios and thermal history imposed are developed in isotactic propylene-co-1-pentene-co-1-hexene terpolymers. Accordingly, their mechanical behavior is strongly dependent on total comonomers content, ratio of both counits and the crystalline characteristics (mainly crystallinity, different polymorphs existing at a given specimen and crystallites perfection). The capacity of developing the trigonal form is a key variable that affects structural and mechanical parameters, leading to unusual dependences of global composition with: the crystallinity degree; the values of storage and indentation modulus as well as hardness; and, the intensity of the main relaxation associated with glass transition together with the indentation pseudo-compliance function.

This unusual variation with overall composition involves a reduction in crystallinity values as comonomers content increases up to the T10 series but a subsequent increase at the highest T14 global composition associated with the development of this trigonal polymorph. This rise is superior in the slowly cooled samples than in the $\mathrm{Q}$ ones.

The presence of larger amounts in 1-hexene appears to have an influence on the final crystallinity, on crystalline morphology and on the mobility within the amorphous regions. In fact, mesomorphic entities and the totally amorphous state are easily obtained in the terpolymers at accessible cooling rates.

The main $\beta$ relaxation is dependent on global composition and comonomers ratio. It moves to lower temperatures as increasing comonomers content and as 1-hexene ratio is raised at a given overall composition. Development of trigonal form in the T14 series clearly varies the expected dependence on total comonomers content.

Terpolymers become progressively softer except for the T14 series. The capability of developing the trigonal polymorph in all the T14 terpolymers increases their 
crystallinity and an anomalous variation is observed in their mechanical parameters related to rigidity.

The KWW stretched exponential function yields an accurate description of the indentation depth variation during the creep period in the indentation experiments. Terpolymers initially become more compliant as global content increases up to 10 mol\%, composition at which pseudo-compliance displays a maximum value. In addition, $J^{*}{ }_{i t}(\infty)$ is dependent on the nature of the comonomer, so that the Tx-25Pe-75He terpolymers creep more easily than the Tx-75Pe-25He and Tx-50Pe-50He ones at similar total comonomers content. The highest content in 1-hexene leads to the highest global mobility and, therefore, the highest deformability under constant load of the resultant terpolymers.

\section{Acknowledgements}

The financial support from projects MAT2013-47972-C2-1-P and MAT2013-47972C2-2-P (MINECO) and from project MAT2016-79869-C2-1-P (AEI/FEDER, UE) is greatly acknowledged. The synchrotron experiments were performed at beamline BL11NCD at ALBA Synchrotron Light Facility with the collaboration of ALBA staff.

\section{REFERENCES}

1. P. Galli, G.Vecellio, Technology: driving force behind innovation and growth of polyolefins, Prog. Polym. Sci. 26 (2001) 1287-1336.

2. S. Brückner, S.V. Meille, V. Petraccone, B. Pirozzi, Polymorphism in isotactic polypropylene Prog. Polym. Sci. 16 (1991) 361-404.

3. J.J. Varga, Supermolecular structure of isotactic polypropylene, Mater. Sci. 27 (1992) 2557-2579.

4. J.J. Varga, $\beta$-Modification of isotactic polypropylene: preparation, structure, processing, properties, and application, Macromol. Sci., Phys. B 41 (2002) 1121-1171.

5. R. Krache; R. Benavente; J.M. López-Majada; J.M. Pereña; M.L. Cerrada; E. Pérez, Competition between alpha, beta and gamma polymorphs in a beta-nucleated metallocene isotactic polypropylene, Macromolecules 40 (2007) 6871-6878.

6. E. Pérez, J.M. Gómez-Elvira, R. Benavente, M.L. Cerrada, Tailoring the Formation Rate of the Mesophase in Random Propylene-co-1-Pentene Copolymers, Macromolecules 45 (2012) 6481-6490.

7. J. Arranz-Andrés, R. Parrilla, M.L. Cerrada, E. Pérez, Mesophase Formation in Random Propyleneco-1-Octene Copolymers, Macromolecules 46 (2013) 8557-8568.

8. G. Natta; P. Corradini, Strucutre and properties of isotactic polypropylene, Nuovo Cimento Suppl. 15 (1960) 40-51.

9. A. Turner-Jones, J.M. Aizlewood, D. R. Beckett, Crystalline forms of isotactic polypropylene, Makromol. Chem. 75 (1964) 134-158.

10. P. Corradini, C. de Rosa, G. Guerra, V. Petraccone, Comments on the possibility that the mesomorphic form of isotactic polypropylene is composed of small crystals of the beta-crystalline form, Polym. Commun. 30 (1989) 281-285. 
11. S. Brückner, S.V. Meille, Non-parallel chains in crystalline gamma-isotactic polypropylene, Nature 340 (1989) 455-457.

12. S.V. Meille, D. Ferro, S. Brückner, A.J. Lovinger, F.J. Padden, Structure of beta-isotactic polypropylene - a long-standing structural puzzle, Macromolecules 27 (1994) 2615-2622.

13. E. Pérez, D. Zucchi, M.C. Sacchi, F. Forlini, A. Bello, Obtaining the gamma phase in isotactic polypropylene: effect of catalyst system and crystallization conditions, Polymer 40 (1999) 675-681.

14. R.G. Alamo; M.-H. Kim; M.J. Galante; J.R. Isasi; L. Mandelkern, Structural and kinetic factors governing the formation of the gamma polymorph of isotactic polypropylene, Macromolecules 32 (1999) 4050-4064.

15. I.L. Hosier, R.G. Alamo, P. Esteso, J.R. Isasi, L. Mandelkern, Formation of the alpha and gamma polymorphs in random metallocene-propylene copolymers. Effect of concentration and type of comonomer, Macromolecules 36 (2003) 5623-5636.

16. J. Arranz-Andrés, R. Benavente, E. Pérez, M.L. Cerrada, Structure and mechanical behavior of the mesomorphic form in a propylene- $b$-EPR copolymer and its comparison with other thermal treatments, Polymer J. 35 (2003) 766-777.

17. A. Dimeska, P.J. Phillips, High pressure crystallization of random propylene-ethylene copolymers: alpha-gamma Phase diagram, Polymer 47 (2006) 5445-5456.

18. B. Poon, M. Rogunova, A. Hiltner, E. Baer, S.P. Chum, A. Galeski. E, Piorkowska, Structure and properties of homogeneous copolymers of propylene and 1-hexene, Macromolecules 38 (2005) 12321243.

19. B. Lotz, J. Ruan, A. Thierry, G.C. Alfonso, A. Hiltner, E. Baer, E. Piorkowska, A. Galeski, A structure of copolymers of propene and hexene isomorphous to isotactic poly(1-butene) form I, Macromolecules 39 (2006) 5777-5781.

20. C. De Rosa, S. Dello Iacono, F. Auriemma, E. Ciaccia, L. Resconi, Crystal structure of isotactic propylene-hexene copolymers: The trigonal form of isotactic polypropylene, Macromolecules 39 (2006) 6098-6109.

21. C. De Rosa, F. Auriemma, P. Corradini, O. Tarallo, S. Dello Iacono, E. Ciaccia, L. Resconi, Crystal structure of the trigonal form of isotactic polypropylene as an example of density-driven polymer structure, J. Am. Chem. Soc. 128 (2006) 80-81.

22. C. De Rosa, F. Auriemma, O. Ruiz de Ballesteros, L. Resconi, I. Camurati, Tailoring the Physical Properties of Isotactic Polypropylene through Incorporation of Comonomers and the Precise Control of Stereoand Regioregularity by Metallocene Catalysts, Chem. Mater. 19 (2007) 5122-5130.

23. C. De Rosa, F. Auriemma, O. Ruiz de Ballesteros, D. De Luca, L. Resconi, The Double Role of Comonomers on the Crystallization Behavior of Isotactic Polypropylene: Propylene-Hexene Copolymers, Macromolecules 41 (2008) 2172-2177.

24. C. De Rosa, F. Auriemma, O.R. de Ballesteros, S. Dello Iacono, D. De Luca, L. Resconi, StressInduced Polymorphic Transformations and Mechanical Properties of Isotactic Propylene-Hexene Copolymers, Cryst. Growth Des. 9 (2009) 165-176.

25. C. De Rosa, F. Auriemma, G. Talarico, O. Ruiz de Ballesteros, Structure of Isotactic PropylenePentene Copolymers, Macromolecules 40 (2007) 8531-8532.

26. C. De Rosa, O. R. Ballesteros, F. Auriemma and M. R. Di Caprio, Crystal Structure of the Trigonal Form of Isotactic Propylene-Pentene Copolymers: An Example of the Principle of Entropy-Density Driven Phase Formation in Polymers, Macromolecules 2012, 45, 2749-2763.

27. P. Stagnaro, L. Boragno, M. Canetti, F. Forlini, F. Azzurri, G.C. Alfonso, Crystallization and morphology of the trigonal form in random propene/1-pentene copolymers, Polymer 50 (2009) 52425249.

28. E. Perez, M.L. Cerrada, R. Benavente, J.M. Gomez-Elvira, Enhancing the formation of the new trigonal polymorph in isotactic propene-1-pentene copolymers: determination of the X-ray crystallinity, Macromol. Res. 19 (2011) 1179-1185.

29. M.L. Cerrada, M.J. Polo-Corpa, R. Benavente, E. Pérez, T. Velilla, R. Quijada, Formation of the New Trigonal Polymorph in iPP-1-Hexene Copolymers. Competition with the Mesomorphic Phase, Macromolecules 42 (2009) 702-708. 
30. L. Boragno, P. Stagnaro, F. Forlini, F. Azzurri, G.C. Alfonso, The trigonal form of i-PP in random C3/C5/C6 terpolymers, Polymer 54 (2013) 1656-1662.

31. A. García-Peñas, J.M. Gómez-Elvira, E. Pérez, M,L, Cerrada, Isotactic Poly(propylene-co-1-penteneco-1-hexene) Terpolymers: Synthesis, Molecular Characterization and Evidence of the Trigonal Polymorph, J. Polym. Sci., Part A: Polym. Chem. 51 (2013) 3251-3259.

32. A. García-Peñas, J.M. Gómez-Elvira, R. Barranco-García, E. Pérez, M.L. Cerrada, Trigonal form as a tool for tuning mechanical behavior in poly(propylene-co-1-pentene-co-1-heptene) terpolymers, Polymer 99 (2016) 112-121.

33. A. García-Peñas, J.M. Gómez-Elvira, V Lorenzo, E. Pérez; M.L. Cerrada, Synthesis, molecular characterization, evaluation of polymorphic behavior and indentation response in isotactic poly(propylene-co-1-heptene) copolymers, Eur. Polym. J. 64 (2015) 52-61.

34. A. García-Peñas, J.M. Gómez-Elvira, M.U. de la Orden, M.L. Cerrada, E Pérez, Mesophase features in isotactic poly(propylene-co-1-heptene) copolymers, Polym. Int. 65 (2016) 596-604.

35. J. Arranz-Andrés, M.U. de la Orden, J. Martínez Urreaga, J.M. Gómez-Elvira, E. Pérez, M.L. Cerrada, Fourier Transform Infrared Spectroscopy Study of Polymorphism in Propylene-co-1Pentene Copolymers: Trigonal Form Identification, Eur. Polym. J. 63, 227-236 (2015).

36. A.C. Fischer-Cripps, Nanoindentation (3rd. edition), Springer New York, 2011.

37. M.R. VanLandingham, J.S. Villarrubia, W.F. Guthrie, G.F. Meyers, Nanoindentation of Polymers: an overview, Macromol. Symp. 167 (2001) 15-44.

38. A. García-Peñas, J.M. Gómez-Elvira, E. Pérez, M.L. Cerrada, Microstructure of Metallocene Isotactic Propylene-co-1-Pentene-co-1-Hexene Terpolymers, J. Polym. Sci., Part A: Polym. Chem. 52 (2014) 2537-2547.

39. W.C. Oliver, G.M. Pharr, An Improved Technique for Determining Hardness and Elastic Modulus Using Load and Displacement Sensing Indentation Experiments. J. Mater. Res. 7 (1992) 1564-1583.

40. G. Feng, A.H.W. Ngan, Effects of creep and thermal drift on modulus measurement using depth sensing indentation, J. Mater. Res. 17 (2002) 660-668.

41. K. Johnson, The correlation of indentation experiments, J. Mech. Phys. Solids 18 (1970) 115-126.

42. P.C. Chung, E. Glynos, P. F. Green, The elastic mechanical response of supported thin polymer films, Langmuir 30 (2014) 15200-15205.

43. L. Li, L.M. Encarnacao, K.A. Brown, Polymer nanomechanics: Separating the size effect from the substrate effect in nanoindentation, Appl. Phys. Lett. 110 (2017) 043105.

44. A. García-Peñas, J.M. Gómez-Elvira, M.L. Cerrada, E. Pérez, Dependence of phase transitions on composition in isotactic poly(propylene-co-1-pentene-co-1-hexene) terpolymers, RSC Adv. 6 (2016) 82907-82915.

45. J.M. López Majada, H. Palza, J.L. Guevara, R. Quijada, M.C. Martínez, R. Benavente, J.M. Pereña, E. Pérez, M.L. Cerrada, Metallocenic Copolymers of Propene and 1 Hexene: Influence of Comonomer Content and Thermal History on the Structure and Mechanical Properties, J. Polym. Sci., Part B: Polym. Phys. 44 (2006) 1253-1267.

46. H. Palza, J.M. López-Majada, R. Quijada, J.M. Pereña, R. Benavente, E. Pérez, M.L. Cerrada, Comonomer Length Influence on the Structure and Mechanical Response of Metallocenic Polypropylenic Materials, Macromol. Chem. Phys. 209 (2008) 2259-2267.

47. N.G. McCrum, B.E. Read, G. Williams, Anelastic and Dielectric Effects in Solid Polymers; Dover, New York, 1991.

48. O. Prieto, J.M. Pereña, R. Benavente, E. Pérez, M.L. Cerrada, Viscoelastic Relaxation Mechanisms of Conventional Polypropylene Toughened by a Plastomer, J. Polym. Sci., Part B: Polym. Phys. 41 (2003) 1878-1888.

49. C. Jourdan, J.Y. Cavaille, J. Perez, Mechanical Relaxations in Polypropylene - a New Experimental and Theoretical Approach, J. Polym. Sci., Part B: Polym. Phys. 27 (1989) 2361-2384.

50. M.J. Polo-Corpa, R. Benavente, T. Velilla, R. Quijada, E. Pérez, M. L. Cerrada, Development of mesomorphic form in propene/higher $\alpha$-olefin copolymers at intermediate comonomer content and its effect on properties, Eur. Polym. J. 46 (2010) 1345-1354 
51. R.H. Boyd, S.M. Breitling, Conformational-Analysis of Crankshaft Motions in Polyethylene. Macromolecules 7 (1974) 855-862.

52. M.L. Cerrada, R. Benavente, E. Pérez, Crystalline structure and viscoelastic behavior in composites of a metallocenic ethylene-1-octene copolymer and glass fiber, Macromol. Chem. Phys. 203 (2002) $718-726$.

53. C. Fonseca, J.M. Pereña, R. Benavente, M.L. Cerrada, A. Bello, E. Pérez, Microhardness and thermal study of the annealing effects in vinyl alcohol-ethylene copolymers, Polymer 36 (1995) 1887-1892.

54. M.L. Cerrada, J.L. de la Fuente, M. Fernández-García, E.L. Madruga, Viscoelastic and mechanical properties of poly(butyl acrylate-g-styrene) copolymers, Polymer 42 (2001) 4647-4655.

55. A.C. Fischer-Cripps, A simple phenomenological approach to nanoindentation creep, Mater. Sci. Eng. A 385 (2004) 74-82.

56. G. Peng, T. Zhang, Y. Feng, Y. Huan, Determination of shear creep compliance of linear viscoelastic-plastic solids by instrumented indentation, Polym. Testing, 31 (2012) 1038-1044.

57. V. Lorenzo, C. Acebo, X. Ramis, À. Serra, Mechanical Characterization of Sol-Gel Epoxy-Silylated Hyperbranched Poly(ethyleneimine) Coatings by Means of Depth Sensing Indentation Methods, Progress in Organic Coatings 92 (2016) 16-22.

58. G. Williams, D.C. Watts, Non-symmetrical dielectric relaxation behaviour arising from a simple empirical decay function, Trans. Faraday Soc. 66 (1970) 80-85.

59. J.H. Wu, Q. Jia, The heterogeneous energy landscape expression of KWW relaxation, Scientific Reports 6 (2016) Article number: 20506. 